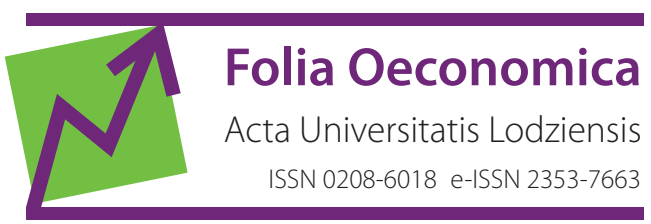

www.czasopisma.uni.lodz.pl/foe/

6(332) 2017

DOI: http://dx.doi.org/10.18778/0208-6018.332.05

\author{
Aleksandra Baszczyńska \\ University of Łódź, Faculty of Economics and Sociology, Department of Statistical Methods, \\ albasz@uni.lodz.pl
}

\title{
One Value of Smoothing Parameter vs Interval of Smoothing Parameter Values in Kernel Density Estimation
}

\begin{abstract}
Ad hoc methods in the choice of smoothing parameter in kernel density estimation, although often used in practice due to their simplicity and hence the calculated efficiency, are characterized by quite big error. The value of the smoothing parameter chosen by Silverman method is close to optimal value only when the density function in population is the normal one. Therefore, this method is mainly used at the initial stage of determining a kernel estimator and can be used only as a starting point for further exploration of the smoothing parameter value. This paper presents ad hoc methods for determining the smoothing parameter. Moreover, the interval of smoothing parameter values is proposed in the estimation of kernel density function. Basing on the results of simulation studies, the properties of smoothing parameter selection methods are discussed.
\end{abstract}

Keywords: kernel density estimation, smoothing parameter, ad hoc methods

JEL: C10, C13, C14 


\section{Introduction}

The decision about the value of the smoothing parameter in kernel method is one of the most crucial in the procedures of kernel statistical inference. Finding the proper value of the smoothing parameter and using it in kernel methods are considered in literature (cf.: Heidenreich et al., 2013; Li, Racine, 2007; Baszczyńska, 2014; 2016).

Kernel method of statistical inference may be used in estimation, among others, of density function, distribution function and regression function as well as in hypothesis testing. When kernel statistical procedures are used in practice, the researcher is obliged to make a decision about parameters of kernel methods: kernel function and smoothing parameter. The idea of kernel method comes from Rosenblatt and Parzen's kernel density estimation. According to this approach kernel estimator $\hat{f}_{n}(x)$ of density $f(x)$ of random variable $X$ is defined in the following way (cf.: Kulczycki, 2005; Silverman, 1996; Wand, Jones, 1995):

$$
\hat{f}_{n}(x)=\frac{1}{n h_{n}} \sum_{i=1}^{n} K\left(\frac{x-X_{i}}{h_{n}}\right),
$$

where:

$X_{1}, X_{2}, \ldots, X_{n}$ is the random sample from the population with unknown density function $f(x)$,

$n$ is the sample size, $h_{n}$ is the smoothing parameter, $K(u)$ is the kernel function which plays the role of the weighting function.

The smoothing parameter $h_{n}$, which controls the smoothness of the estimator fulfils the following conditions: $\lim _{n \rightarrow \infty} h=0$ and $\lim _{n \rightarrow \infty} n h=\infty$. Throughout this paper $h=h_{n}$ will be used to simplify the notation.

Kernel function $K(u)$ is the function which is symmetric and unimodal and the following conditions are fulfilled:

$$
\left\{\begin{array}{l}
\int_{-\infty}^{\infty} K(u) d u=1 \\
\int_{-\infty}^{\infty} u K(u) d u=0 \\
\int_{-\infty}^{\infty} u^{2} K(u) d u=\kappa_{2}>0 .
\end{array}\right.
$$


Thekernel function of such kind is called the second order kernel function(orclassical kernel function). Gaussian kernel function $K_{G}(u)=\frac{1}{\sqrt{2 \pi}} \exp \left(-\frac{1}{2} u^{2}\right)$ and Epanechnikov kernel function $K_{E}(u)=\left\{\begin{array}{l}\frac{3}{4}\left(1-u^{2}\right) \text { for }|u| \leq 1, \\ 0 \text { for }|u|>1\end{array}\right.$ are the examples of second order kernel functions and these are the ones which are mostly used in kernel methods of estimation and testing hypothesis.

The paper deals with the problem of choosing the proper value of smoothing parameter in kernel density estimation and discusses the approach of the starting point in the procedure of constructing the kernel estimator basing not only on one value of smoothing parameter, chosen on base of some known and often used ad hoc methods, but on the interval of values of smoothing parameter. In ad hoc methods the population distribution is assumed, therefore using them, the user has to take into account the error connected with the assumption being or not being fulfilled. In addition this is strongly connected with the character of this assumption. The user in many cases is not able to evaluate which distribution should be assumed, that is to say, which ad hoc method is appropriate in this situation. Regarding not one value but the interval of the values can mean the compilation of the results of different methods used in choosing the value of smoothing parameter. This way, combing the interval of smoothing parameter values in kernel density estimation makes the procedure of estimation strengthened and easier in use. The procedure of applying the interval of smoothing parameter values in subjective method, in kernel density estimation results in using this method in broader range of applications without the risk emerging from taking inappropriate assumption of the population distribution. The idea of the interval of smoothing parameter values includes the subjective method of choosing the smoothing parameter but with the direct indication of acceptable and well-balanced values. Choosing one value for the construction of the kernel density estimator from this interval is distinctly easier for the users.

The objective of this paper is to present and analyse properties of the new procedure of choosing the smoothing parameter in kernel density function.

The paper is organized as follows. Section 2 describes the ad hoc methods of choosing the smoothing parameter and presents the idea of interval of smoothing parameter values. Section 3 provides the results of simulation study and examples of kernel density estimation usage with the discussions and tips for practical use of regarded methods. Finally, Section 4 describes the conclusions. 


\section{Ad hoc methods of choosing the smoothing parameter}

In many practical implementations of kernel estimator of density function, the subjective method of choosing the smoothing parameter is used. This means constructing many density kernel estimators with different values of smoothing parameter, evaluation of these estimators, taking into account the values of parameters and finally choosing a value of the parameter for which the kernel estimator is acceptable for researcher in some previously defined sense. This approach requires a great deal of experience of the organizer of the research and it is time consuming. Practical approach means that as a starting point the big value of smoothing parameter is used and then it is gradually decreased.

An entirely different approach, called 'objective methods of choosing a smoothing parameter', is based on the estimation criteria and in particular on some goodness measures of the kernel density estimator. These methods are called quick and dirty or methods with reference to distribution.

The asymptotic mean integrated squared error of the following form:

$$
\text { AMISE }[\hat{f}(x)]=\frac{\kappa}{n h}+\frac{h^{4} \kappa_{2}^{2}}{4} \int_{-\infty}^{+\infty}\left[f^{(2)}(x)\right]^{2} d x \text {, }
$$

where:

$$
\begin{aligned}
& \kappa=\int_{-\infty}^{+\infty} K^{2}(u) d u, \\
& \kappa_{k}=\int_{-\infty}^{+\infty} u^{k} K(u) d u
\end{aligned}
$$

is mostly used as the criterion for density estimation.

The minimization of the criterion (3) leads to the smoothing parameter:

$$
h_{\text {AMISE }}=\left(\frac{\kappa}{\kappa_{2}^{2} R\left(f^{(2)}\right)}\right)^{\frac{1}{5}} n^{-\frac{1}{5}},
$$

where:

$$
R\left(f^{(2)}\right)=\int_{-\infty}^{+\infty}\left[f^{(2)}(x)\right]^{2} d x .
$$


In practical Silverman rule (normal scale rule) the normal density is used in (4) as the reference density with the variance $\sigma^{2}$, where:

$$
\int_{-\infty}^{+\infty}\left[f^{(2)}(x)\right]^{2} d x=\frac{3}{8 \sigma^{5} \sqrt{\pi}} \approx 0.212 \sigma^{-5}
$$

When Gaussian kernel function for which $\int_{-\infty}^{+\infty} u^{2} K(u) d u=1$ and $\int_{-\infty}^{+\infty} K^{2}(u) d u=\frac{\sqrt{\pi}}{2}$ is applied, the smoothing parameter has the form:

$$
\hat{h}_{R R, G}=\frac{1}{\sqrt[10]{4 \pi}} \frac{1}{\sqrt[5]{\frac{3}{8 \sqrt{\pi}}}} \sigma n^{-\frac{1}{5}} \approx 1.06 \sigma n^{-\frac{1}{5}} \text { and } \hat{h}_{R R, G}=0.79 R n^{-\frac{1}{5}},
$$

where $\sigma$ can be estimated basing on the sample and $R$ is the interquartile range from the sample.

For Gaussian kernel function a smoothing parameter selector is the following (cf.: Heidenreich et al., 2013; Li, Racine, 2007; Wand, Jones, 1995; Scott, 2015):

$$
\hat{h}_{R R, G}=1.06 \min \left(\hat{\sigma}, \frac{\hat{R}}{1.34}\right) n^{-\frac{1}{5}}
$$

where:

$\hat{\sigma}$ is the estimate of standard deviation,

$\hat{R}$ is sample interquartile range.

The modification of (5) is made to avoid the problem of bimodality:

$$
\hat{h}_{R R, G}=0.9 A n^{-\frac{1}{5}}, \text { where } A=\min \left(\hat{\sigma}, \frac{\hat{R}}{1.34}\right) \text {. }
$$

When Epanechnikov kernel function, for which $\int_{-\infty}^{+\infty} u^{2} K(u) d u=1$ and $\int_{-\infty}^{+\infty} K^{2}(u) d u \approx 0.27$ is used, the smoothing parameter is the following:

$$
\hat{h}_{R R, E} \approx 1.05 \sigma n^{-\frac{1}{5}} \text {, }
$$

where $\sigma$ can be estimated basing on the sample.

The next quick and simple smoothing parameter selector is also based on minimization of asymptotic mean integrated squared error (3). It can be noticed that the biggest smoothing can be done for the smallest value of $R\left(f^{(2)}\right)$. This is attained for beta $(4,4)$ distribution and this smoothing parameter method is called oversmooth- 
ing or maximal smoothing principle. According to this rule the smoothing parameter for second order kernel function bandwidth selector is the following:

$$
\hat{h}_{M S}=\frac{3}{35^{5}} \hat{\sigma}\left(\frac{R(K)}{\kappa_{2}^{2}}\right)^{\frac{1}{5}} n^{-\frac{1}{5}} \text {. }
$$

In particular, for Gaussian and Epanechnikov kernel functions, the smoothing parameter selectors are, respectively (Horová et al., 2012):

$$
\begin{aligned}
& \hat{h}_{M S, G}=1.144 \hat{\sigma} n^{-\frac{1}{5}} . \\
& \hat{h}_{M S, E}=2.532 \hat{\sigma}^{-\frac{1}{5}} .
\end{aligned}
$$

The generalization of the quick and simple methods of choosing the smoothing parameter is the idea of acceptable interval of smoothing parameters introduced by Horová et al. (2012). This interval has the following form:

$$
H_{n}=\left[\min \left|X_{i}-X_{j}\right|, \hat{h}_{M S}\right] \text {, }
$$

where min $\left|X_{i}-X_{j}\right|$ denotes the minimal distance between points $X_{i}$ and $X_{j}$, for $i$, $j=1,2, \ldots, n, i \neq j$, and $\hat{h}_{M S}$ is described for second order kernel function in (7).

The new smoothing parameter interval is proposed:

$$
H=\left[\hat{h}_{R R, G}, \hat{h}_{M S}\right] \text {, }
$$

where $\hat{h}_{R R, G}$ is the smoothing parameter calculated using Silverman reference rule and is defined in (6) and $\hat{h}_{M S}$ is maximal smoothing parameter defined in (7).

The above interval of values of smoothing parameter is constructed using only quick and simple methods, which ensure the simplicity and quickness of calculations (ad hoc methods are well prepared in some statistical packages), but on the other hand it focuses on different features of estimated density function, from normal distributions (assumption in reference rule) to distributions which ensure high level of smoothing (maximum smoothing method). The procedure may include determining the interval (8) and then using, for example, the midpoint of this interval. 


\section{Results of simulation study}

The objective of the simulation study is to analyze the properties of the intervals of smoothing parameter proposed in section 2, where the length of the intervals is the main compering criterion. Different distributions from which samples are drawn and different values of sample sizes are also taken into account in the attempt of analyzing the properties of smoothing parameter interval.

The main elements in the simulation study description are the following:

1) nineteen populations representing distributions of different features with the special emphasis of the distribution's dispersion and asymmetry. The populations are grouped into some classes, and this way they represent a wide range of unimodal distributions. The distributions with appropriate parameters are presented in table 1 ;

2) samples $X_{1}, X_{2}, \ldots, X_{n}$ of different sizes $n=10,20, \ldots, 100$ drawn from populations;

3) the values of smoothing parameters which are calculated to construct the smoothing parameter interval;

4) the lengths of the intervals are compared;

5) the number of repetition was set to 10000 ;

6) all calculations are made using Mathworks software MATLAB, version R2014a.

Table 1. The population distributions considered in the simulation study

\begin{tabular}{|c|c|}
\hline Classes of distributions & Distribution's parameters \\
\hline \multirow{4}{*}{$\begin{array}{c}\text { Normal distribution } X \sim N(\mu, \sigma), \\
\mu \text { expected value, } \\
\sigma \text { standard deviation }\end{array}$} & $X \sim N(10,1)$ \\
\hline & $X \sim N(10,5)$ \\
\hline & $X \sim N(10,8)$ \\
\hline & $X \sim N(10,10)$ \\
\hline \multirow{5}{*}{$\begin{array}{c}\text { Noncentral } t \text {-Student distribution } \\
X \sim N t-S(k, \delta), \\
k \text { degrees of freedom, } \\
\delta \text { noncentrality parameter }\end{array}$} & $X \sim N t-S(5,1)$ \\
\hline & $X \sim N t-S(5,-10)$ \\
\hline & $X \sim N t-S(5,10)$ \\
\hline & $X \sim N t-S(20,-10)$ \\
\hline & $X \sim N t-S(20,10)$ \\
\hline \multirow{5}{*}{$\begin{array}{c}\text { Noncentral chi-squared distribution } \\
X \sim N \chi^{2}(k, \delta), \\
k \text { degrees of freedom, } \\
\delta \text { noncentrality parameter }\end{array}$} & $X \sim N \chi^{2}(5,1)$ \\
\hline & $X \sim N \chi^{2}(5,10)$ \\
\hline & $X \sim N \chi^{2}(5,20)$ \\
\hline & $X \sim N \chi^{2}(20,10)$ \\
\hline & $X \sim N \chi^{2}(20,20)$ \\
\hline
\end{tabular}




\begin{tabular}{|c|c|}
\hline Classes of distributions & Distribution's parameters \\
\hline \multirow{2}{*}{ Noncentral Fisher-Snedecor distribution } & $X \sim N F-\mathrm{S}(5,5,1)$ \\
\cline { 2 - 2 } \begin{tabular}{c|}
$X \sim N F-S\left(k_{1}, k_{2}, \delta\right)$ \\
$k_{1}, k_{2}$ degrees of freedom \\
$\delta$ noncentrality parameter
\end{tabular} & $X \sim N F-S(5,5,10)$ \\
\cline { 2 - 2 } & $X \sim N F-S(5,20,10)$ \\
\cline { 2 - 2 } & $X \sim N F-S(20,5,10)$ \\
\cline { 2 - 2 } & $X \sim N F-S(20,20,10)$ \\
\hline
\end{tabular}

Source: own elaboration

First class of distributions is characterized by symmetry but different values of standard deviation, which is used to distinguish populations. The class of noncentral $t$-Student distributions includes symmetric distribution for noncentrality parameter $\delta=1$ and negatively skewed distributions for negative values of noncentrality parameter and positively skewed distributions for positive values of noncentrality parameter. In the class of chi-squared and Fisher-Snedecor distributions noncentrality parameter influences directly the strength of asymmetry, the bigger the value of $\delta$, the stronger the asymmetry is.

The results of the simulation study for chosen sample sizes $n=10,50,100$ are presented in tables $2-5$.

Table 2. Intervals of smoothing parameter values in kernel density estimation for chosen sample sizes for samples from normally distributed populations

\begin{tabular}{|c|c|c|c|}
\hline Population distribution & Sample size & Smoothing parameter interval & Length of interval \\
\hline \multirow{3}{*}{$X \sim N(10,1)$} & 10 & {$[0.39 ; 0.44]$} & 0.05 \\
\cline { 2 - 4 } & 50 & {$[0.47 ; 0.51]$} & 0.04 \\
\cline { 2 - 4 } & 100 & {$[0.43 ; 0.46]$} & 0.03 \\
\hline \multirow{3}{*}{$X \sim N(10,5)$} & 10 & {$[3.48 ; 3.68]$} & 0.20 \\
\cline { 2 - 4 } & 50 & {$[2.32 ; 2.50]$} & 0.18 \\
\cline { 2 - 4 } & 100 & {$[1.80 ; 1.95]$} & 0.15 \\
\hline \multirow{3}{*}{$X \sim N(10,8)$} & 10 & {$[4.40 ; 4.73]$} & 0.33 \\
\cline { 2 - 4 } & 50 & {$[3.60 ; 3.88]$} & 0.28 \\
\cline { 2 - 4 }$X \sim N(10,10)$ & 100 & {$[3.79 ; 3.99]$} & 0.20 \\
\hline & 10 & {$[6.80 ; 7.31]$} & 0.51 \\
\cline { 2 - 4 } & 50 & {$[3.99 ; 4.27]$} & 0.28 \\
\hline
\end{tabular}

Source: own calculations

Table 3. Intervals of smoothing parameter values in kernel density estimation for chosen sample sizes for samples from noncentral $t$-Student distributed populations

\begin{tabular}{|c|c|c|c|}
\hline Population distribution & Sample size & Smoothing parameter interval & Length of interval \\
\hline \multirow{3}{*}{$X \sim N t-S(5,1)$} & 10 & {$[0.55 ; 0.59]$} & 0.04 \\
\cline { 2 - 4 } & 50 & {$[0.63 ; 0.66]$} & 0.03 \\
\cline { 2 - 4 } & 100 & {$[0.42 ; 0.44]$} & 0.02 \\
\hline
\end{tabular}




\begin{tabular}{|c|c|c|c|}
\hline Population distribution & Sample size & Smoothing parameter interval & Length of interval \\
\hline \multirow{3}{*}{$X \sim N t-S(5,-10)$} & 10 & {$[2.99 ; 3.25]$} & 0.26 \\
\cline { 2 - 4 } & 50 & {$[2.25 ; 2.40]$} & 0.15 \\
\cline { 2 - 4 } & 100 & {$[1.70 ; 1.81]$} & 0.11 \\
\hline \multirow{3}{*}{$X \sim N t-S(5,10)$} & 10 & {$[1.60 ; 1.73]$} & 0.13 \\
\cline { 2 - 4 } & 50 & {$[1.91 ; 2.06]$} & 0.15 \\
\cline { 2 - 4 } & 100 & {$[1.80 ; 1.96]$} & 0.16 \\
\hline \multirow{3}{*}{$X \sim N t-S(20,-10)$} & 10 & {$[1.66 ; 1.78]$} & 0.12 \\
\cline { 2 - 4 } & 50 & {$[0.80 ; 0.87]$} & 0.07 \\
\hline \multirow{3}{*}{$X \sim N t-S(20,10)$} & 100 & {$[0.95 ; 1.01]$} & 0.06 \\
\cline { 2 - 4 } & 10 & {$[1.29 ; 1.38]$} & 0.09 \\
\cline { 2 - 4 } & 50 & {$[0.95 ; 1.03]$} & 0.08 \\
\hline
\end{tabular}

Source: own calculations

Table 4. Intervals of smoothing parameter values in kernel density estimation for chosen sample sizes for samples from noncentral chi-squared distributed populations

\begin{tabular}{|c|c|c|c|}
\hline Population distribution & Sample size & Smoothing parameter interval & Length of interval \\
\hline \multirow{3}{*}{$X \sim N \chi^{2}(5,1)$} & 10 & {$[1.84 ; 1.99]$} & 0.15 \\
\cline { 2 - 4 } & 50 & {$[1.42 ; 1.54]$} & 0.12 \\
\cline { 2 - 4 } & 100 & {$[1.45 ; 1.56]$} & 0.11 \\
\hline \multirow{3}{*}{$X \sim N \chi^{2}(5,10)$} & 10 & {$[2.22 ; 3.40]$} & 1.18 \\
\cline { 2 - 4 } & 50 & {$[3.41 ; 3.60]$} & 0.19 \\
\cline { 2 - 4 } & 100 & {$[2.59 ; 2.80]$} & 0.21 \\
\hline \multirow{3}{*}{$X \sim N \chi^{2}(5,20)$} & 10 & {$[5.90 ; 6.30]$} & 0.40 \\
\cline { 2 - 4 } & 50 & {$[4.16 ; 4.48]$} & 0.32 \\
\cline { 2 - 4 }$X \sim N \chi^{2}(20,10)$ & 100 & {$[4.10 ; 4.41]$} & 0.31 \\
\cline { 2 - 4 } & 10 & {$[4.62 ; 4.98]$} & 0.36 \\
\cline { 2 - 4 } & 50 & {$[4.00 ; 5.31]$} & 0.31 \\
\hline \multirow{3}{*}{$X \sim N \chi^{2}(20,20)$} & 100 & {$[3.63 ; 3.92]$} & 0.29 \\
\cline { 2 - 4 } & 10 & {$[5.89 ; 6.35]$} & 0.46 \\
\cline { 2 - 4 } & 50 & {$[5.10 ; 5.50]$} & 0.40 \\
\hline
\end{tabular}

Source: own calculations

Table 5. Intervals of smoothing parameter values in kernel density estimation for chosen sample sizes for samples from noncentral Fisher-Snedecor distributed populations

\begin{tabular}{|c|c|c|c|}
\hline Population distribution & Sample size & Smoothing parameter interval & Length of interval \\
\hline \multirow{3}{*}{$X \sim N F-S(5,5,1)$} & 10 & {$[0.98 ; 1.05]$} & 0.07 \\
\cline { 2 - 4 } & 50 & {$[0.81 ; 0.87]$} & 0.06 \\
\cline { 2 - 4 } & 100 & {$[0.44 ; 0.49]$} & 0.05 \\
\hline
\end{tabular}




\begin{tabular}{|c|c|c|c|}
\hline Population distribution & Sample size & Smoothing parameter interval & Length of interval \\
\hline \multirow{3}{*}{$X \sim N F-S(5,5,10)$} & 10 & {$[1.18 ; 1.27]$} & 0.09 \\
\cline { 2 - 4 } & 50 & {$[1.34 ; 1.42]$} & 0.08 \\
\cline { 2 - 4 } & 100 & {$[1.01 ; 1.08]$} & 0.07 \\
\hline \multirow{3}{*}{$X \sim N F-S(5,20,10)$} & 10 & {$[0.82 ; 0.89]$} & 0.07 \\
\cline { 2 - 4 } & 50 & {$[0.69 ; 0.73]$} & 0.04 \\
\hline \multirow{3}{*}{$X \sim N F-S(20,5,10)$} & 100 & {$[0.66 ; 0.69]$} & 0.03 \\
\cline { 2 - 4 } & 10 & {$[0.66 ; 0.71]$} & 0.05 \\
\cline { 2 - 4 } & 50 & {$[0.53 ; 0.57]$} & 0.04 \\
\hline \multirow{3}{*}{$X \sim N F-S(20,20,10)$} & 100 & {$[0.46 ; 0.50]$} & 0.04 \\
\cline { 2 - 4 } & 10 & {$[0.52 ; 0.56]$} & 0.04 \\
\cline { 2 - 4 } & 100 & {$[0.44 ; 0.47]$} & 0.03 \\
\hline
\end{tabular}

Source: own calculations

When samples are drawn from the symmetric populations the lengths of smoothing parameter intervals in kernel density estimation are in general smaller than in the case of asymmetric populations. It can mean that when distributions are symmetric the selectors of smoothing parameter in Silverman rule and maximum smoothing rule are behaving in similar way. The sign of noncentrality parameter in $t$-Student distributions which indicates the direction of skewness does not influence the length of smoothing parameter interval. When the asymmetry of the population distribution is stronger, the interval is longer (the difference between the two regarded rules: Silverman and maximum smoothing is bigger). It can be noticed that the bigger the sample size, the smaller the length of regarded intervals.

Regarded selectors of smoothing parameter are used in the construction of the kernel density estimator for data from Forbes ranking of the most attractive cities for business in Poland in 2015 (Ranking miast..., 2016). The kernel density estimators are presented for four groups of cities (depending on numbers of inhabitants): big cities, cities with 150000-300000 inhabitants; cities with 50000-150000 inhabitants; cities and communities of fewer than 50000 inhabitants (kernel density estimation with Gaussian kernel function and the midpoint of the interval (8) are used). The results for the net number of enterprises per 1000 inhabitants for these groups of cities are presented in figures 1-4.

In all four groups of cities attractive for business in Poland in 2015 the distributions of the net number of enterprises per 1000 inhabitants are asymmetric (right-sided asymmetry). The strongest asymmetry is noticed in the last group of cities because in this group one of the communities (Lesznowola) is characterized by big number of enterprises per 1000 inhabitants. Despite the fact that the number of observations is small in all groups, the main features of distribution are shown. 


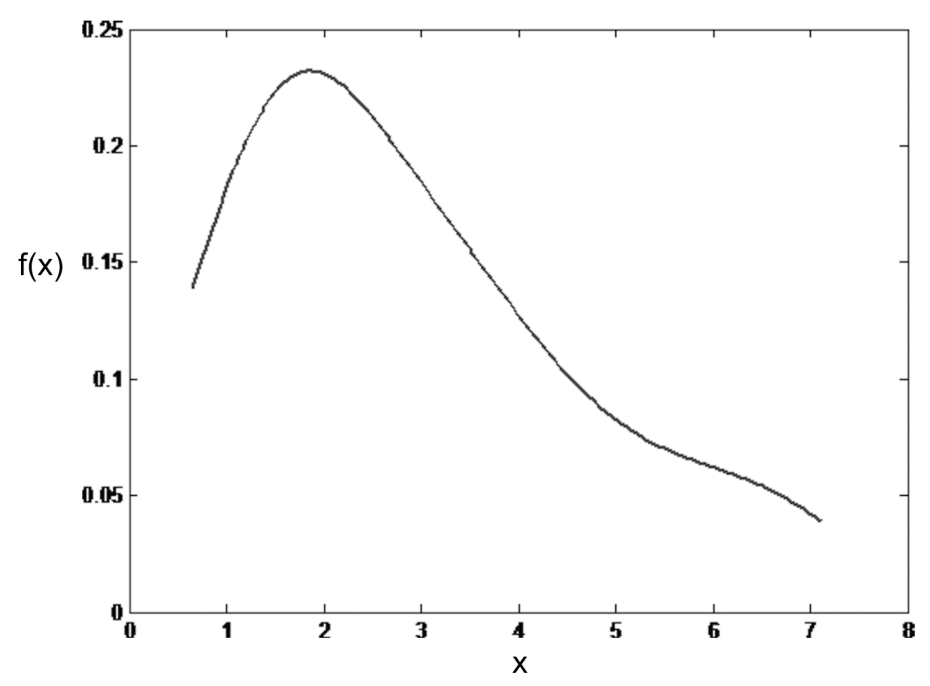

Figure 1. Kernel density estimator for net number of enterprises per 1000 inhabitants for the 10 big cities attractive for business (Gaussian kernel function, $h=0.98$ - the midpoint of the interval of smoothing parameter values)

Source: own elaboration

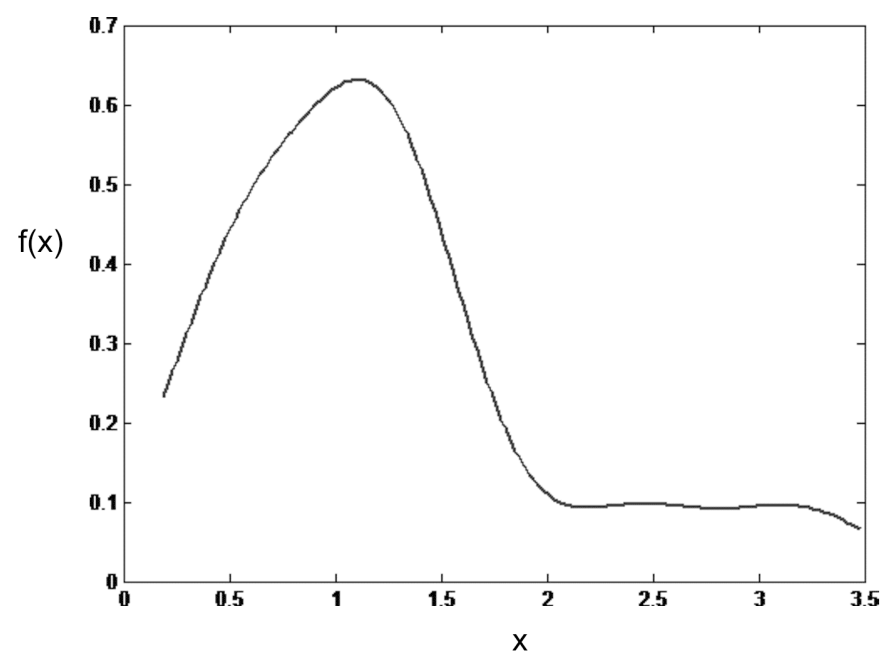

Figure 2. Kernel density estimator for net number of enterprises per 1000 inhabitants for 13 cities with 150000-300000 inhabitants attractive for business (Gaussian kernel function, $h=0.35$ - the midpoint of the interval of smoothing parameter values) 


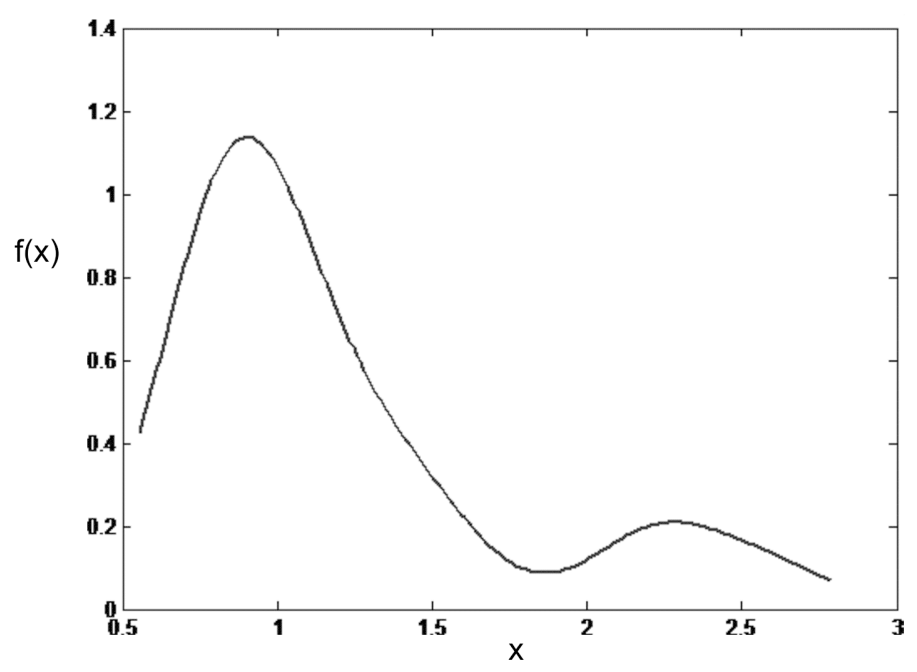

Figure 3. Kernel density estimator for net number of enterprises per 1000 inhabitants for 20 cities with 50000-150000 inhabitants attractive for business (Gaussian kernel function, $h=0.21$ - the midpoint of the interval of smoothing parameter values)

Source: own elaboration.

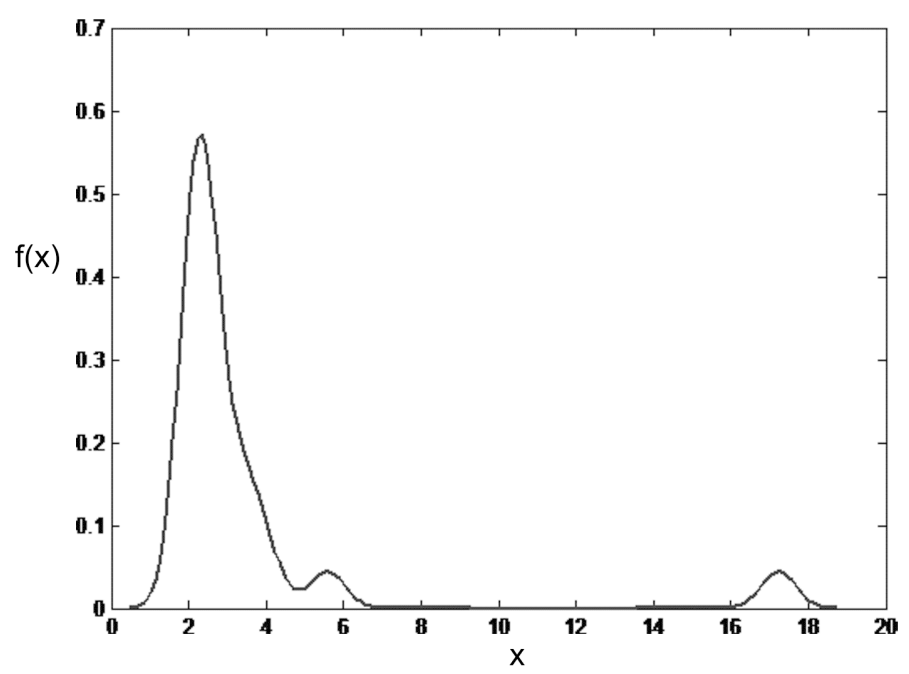

Figure 4. Kernel density estimator for net number of enterprises per 1000 inhabitants for 20 cities and communities with less than 50000 inhabitants attractive for business (Gaussian kernel function, $h=0.45$ - the midpoint of the interval of smoothing parameter values) 


\section{Conclusions}

Choosing the appropriate value of smoothing parameter is often regarded as the most important task in kernel density estimation but in fact it is the procedure where the researcher has to use not only his own experience but also some remarks connected directly with the nature of the examined phenomena. The attempt of restriction of possible values of smoothing parameter is considered, which in fact means a simplification of the procedure. The usage of the two most popular and simple, but quite different selectors, in the construction of the smoothing parameter interval, on one hand makes this procedure user-friendly and on the other, ensures the whole range of all possible levels of smoothing in kernel density estimation. It works quite well not only in symmetric distributions but even when the asymmetry is strong. The researcher can use proposed smoothing parameter interval as a good starting point in determining the appropriate value of smoothing parameter. There is a need of deeper examination of this proposal, for example comparing it with other intervals, such as the acceptable interval of smoothing parameter (Horová et al., 2012).

\section{References}

Baszczyńska A. (2014), Computer-Assisted Choice of Smoothing Parameter in Kernel Methods Applied in Economic Analysis, "Quantitative Methods in Economics", vol. XV, no. 2, pp. 37-46.

Baszczyńska A. (2016), Nonclassical Parameters in Kernel Estimation, "Bulletin de la Société des Sciences et des Letters de Łódź. Recherches sur les Déformations”, vol. LXVI, no. 1, pp. $135-148$.

Heidenreich N., Schindler A., Sperlich S. (2013), Bandwidth Selection for Kernel Density Estimation: a Review of Fully Automatic Selectors, "AStA Advances in Statistical Analysis", vol. 97, no. 4, pp. 403-433.

Horová I., Koláček J., Zelinka J. (2012), Kernel Smoothing in Matlab. Theory and Practice of Kernel Smoothing, World Scientific, New Jersey.

Kulczycki P. (2005), Estymatory jądrowe w analizie systemowej, Wydawnictwa Naukowo-Techniczne, Warszawa.

Li Q., Racine J.S. (2007), Nonparametric Econometrics. Theory and Practice, Princeton University Press, Princeton-Oxford.

Ranking miast atrakcyjnych dla biznesu w 2015 roku (2016), http://www.forbes.pl/ranking-miast-atrakcyjnych-dla-biznesu-efekt-kuli-sniegowej,artykuly,195054,1,4.html [accessed: 12.10.2016].

Silverman B.W. (1996), Density Estimation for Statistics and Data Analysis, Chapman and Hall, London.

Scott D. (2015), Multivariate Density Estimation. Theory, Practice, and Visualization, Wiley, Hoboken-New Jersey.

Wand M.P., Jones M.C. (1995), Kernel Smoothing, Chapman and Hall, London. 


\section{Jedna wartość parametru wygładzania vs. przedział wartości parametru wygładzania w estymacji jądrowej funkcji gęstości}

Streszczenie: Metody ad hoc wyboru parametru wygładzania w estymacji jądrowej funkcji gęstości, chociaż często wykorzystywane w praktyce ze względu na ich prostotę i - co za tym idzie - wysoką efektywność obliczeniową, charakteryzują się dość dużym błędem. Wartość parametru wygładzania wyznaczona metodą Silvermana jest bliska wartości optymalnej tylko wtedy, gdy rozkład funkcji gęstości jest rozkładem normalnym. Dlatego też metoda ta jest stosowana przede wszystkim we wstępnym etapie wyznaczania estymatora jądrowego i stanowi jedynie punkt wyjściowy do dalszych poszukiwań wartości parametru wygładzania. W artykule przedstawione są metody ad hoc wyboru parametru wygładzania oraz zaprezentowana jest propozycja wyznaczania przedziału wartości parametru wygładzania w estymacji jądrowej funkcji gęstości. Na podstawie wyników badań symulacyjnych określone są własności rozważanych metod wyboru parametru wygładzania.

Słowa kluczowe: estymacja jądrowa funkcji gęstości, parametr wygładzania, metody ad hoc JEL: C10, C13, C14

\begin{tabular}{|l|l|}
\hline \multirow{2}{*}{ OPEN ACCESS } & $\begin{array}{l}\text { C) by the author, licensee Łódź University - Łódź University Press, Łódź, Poland. } \\
\text { This article is an open access article distributed under the terms and conditions } \\
\text { of the Creative Commons Attribution license CC-BY } \\
\text { (http://creativecommons.org/licenses/by/3.0/) }\end{array}$ \\
\cline { 2 - 2 } \\
Received: 2017-01-14; verified: 2017-08-21. Accepted: 2017-10-27
\end{tabular}

